\title{
Ambient tectonic tremors in Manawatu, Cape Turnagain, Marlborough, and Puysegur, New Zealand
}

\author{
Pierre Romanet ${ }^{*}$ (1) and Satoshi Ide
}

\begin{abstract}
Tectonic tremors have been detected in New Zealand, including the Gisborne and Manawatu regions in the North Island and along the Alpine Fault in the South Island. Here we report a regional analysis of tremor activity in New Zealand and present a potential relationship between slow and ordinary earthquakes. We first construct a tremor catalog in the Cape Turnagain, Marlborough, and Puysegur regions that spans the 2005-2016 time period using the GeoNet permanent seismometer network, and extend the tremor catalog in Manawatu to cover the same period. We employ an envelope cross-correlation method to detect and locate the seismic events, then extract the tremor-like events using a scaling-law-based criterion that is a function of the event duration and seismic energy, and finally select the tremors by visual inspection. We find that the tremors in Cape Turnagain temporally coincide with known shallow slow slip events in the region. We are also able to relate the increased tremor rates during 2010-2011 and 2014-2015 to two deep slow slip events in Manawatu. However, known slow slip events cannot explain all the increases in the tremor rate throughout Manawatu. Tremors in the South Island occur near recent large earthquakes, such as the 2016 Mw 7.8 Kaikoura Earthquake in Marlborough and 2009 Mw 7.6 Dusky Sound Earthquake in Puysegur, suggesting a possible relationship between slow and fast tectonic processes.
\end{abstract}

Keywords: Tectonic tremors in New Zealand, Slow earthquakes

\section{Introduction}

Tectonic tremors were first detected in Southwest Japan (Obara 2002) and have since been discovered in many regions that possess various tectonic settings, such as the subduction zones in Cascadia (Rogers and Dragert 2003), Mexico (Payero et al. 2008), and south Chile (Ide 2012), a collision zone in Taiwan (Peng and Chao 2008), and the strike-slip fault system along the San Andreas Fault (Nadeau and Dolenc 2005). Tremors are identified as long signals with emergent onsets that often lack impulsive $\mathrm{P}$ and $\mathrm{S}$ waves and possess dominant frequencies in the 2-8 Hz range. They have been shown to be composed of swarms of low-frequency earthquakes (Shelly et al. 2007). Since tremors are often associated with other longer signals, such as very-low-frequency earthquakes

*Correspondence: romanet@eps.s.u-tokyo.ac.jp

Department of Earth and Planetary Science, The University of Tokyo, Bunkȳ̄, Japan
(Ito et al. 2007) or slow slip events (SSEs) (Rogers and Dragert 2003), they are thought to be a single manifestation of the same broadband phenomenon (Ide and Yabe 2014; Kaneko et al. 2018), which can be termed slow earthquakes. The physical mechanisms controlling slow earthquakes and their relationship to large earthquakes have been studied extensively in recent decades (Beroza and Ide 2011; Obara and Kato 2016), and the study of tremor activity in New Zealand may help to better constrain these physical mechanisms.

This study focuses on tectonic tremors in New Zealand, which is at the interface between the Pacific and Australian Plates (Fig. 1). The Pacific Plate is subducting beneath the Australian Plate along the Hikurangi Trough in the North Island, with the velocity of subduction ranging from $6 \mathrm{~cm} /$ year in the north to $2.5 \mathrm{~cm} /$ year in the south (Wallace et al. 2004). Conversely, the Australian Plate is subducting beneath the Pacific Plate along the Puysegur Trough toward the southern end of the South 

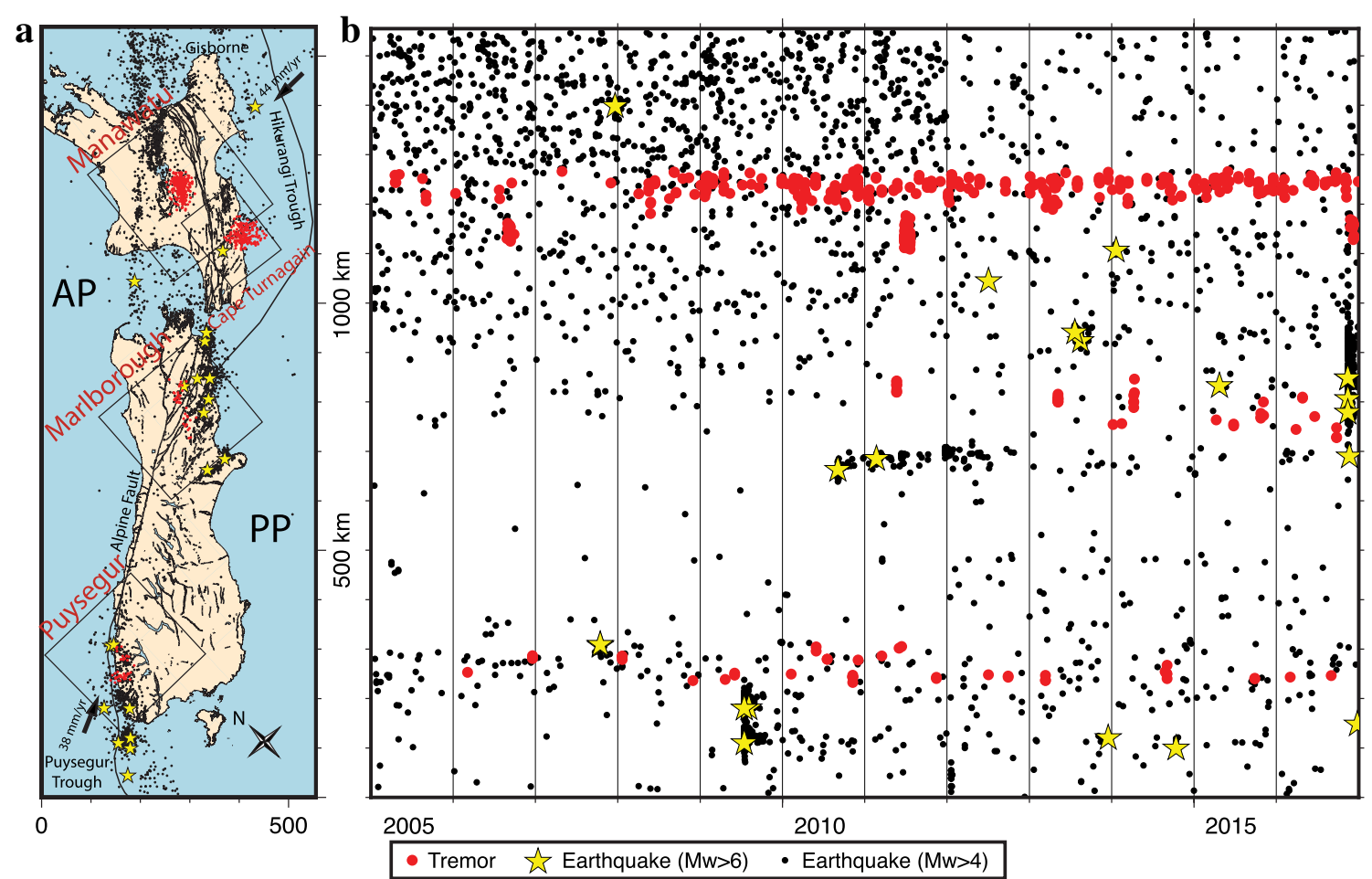

Fig. 1 a Map of the detected tremors in New Zealand. The four rectangular frames indicate the study regions. The fault lineations are from Langridge et al. (2016). The plate boundaries are taken from Bird (2003), and the plate velocities are from the MORVEL model (DeMets et al. 2010). AP Australian Plate, PP Pacific Plate. $\mathbf{b}$ Space-time projection of the detected earthquakes and tremors

Island. These opposing subduction directions are primarily accommodated on the South Island by the Marlborough Fault System in the north and the Alpine Fault. So far, no SSE has been reported in the South Island.

Ambient tectonic tremors have been detected in onshore (Kim et al. 2011; Todd and Schwartz 2016) and offshore Gisborne (Todd et al. 2018), Manawatu (Ide 2012), and along the Alpine Fault (Wech et al. 2012). Triggered tremors have been reported in Manawatu (Fry et al. 2011), and more recently to the north and east of Auckland, in Puysegur, and in Manawatu (along the Taupo Volcanic Zone) following the Kaikoura Earthquake (Peng et al. 2018). Despite these discoveries, tremor studies in New Zealand have generally proven difficult due to the high activity of ordinary earthquakes, which makes automatic detection and location challenging. One of the earlier studies in Gisborne reported only micro-seismicity, but no tremors, associated with SSEs (Delahaye et al. 2009). We therefore construct a tremor catalog using a cross-correlation technique and employ an automated classification with a scaling-law-based criterion and a subsequent manual evaluation to show that ambient tremors occur in Cape Turnagain, on the Marlborough Fault System, and in the Puysegur Subduction Zone. We also continue the study of Ide (2012) in Manawatu to cover the 2005-2016 time period.

\section{Data and methods}

\section{Tremor detection and location}

Tremors are detected and located using an envelope cross-correlation method (Obara 2002; Ide 2010). We use continuous data of broadband and short-period seismometers from stations in the GeoNet network during the 2005-2016 time period. The raw velocity data are first band-pass-filtered between 2 and $8 \mathrm{~Hz}$, squared, lowpass-filtered at $0.1 \mathrm{~Hz}$, and resampled at 1 sample per second. The square root of these data is used as the envelope for the tremor detection. We create successive 300-s time windows, with 150-s overlap, from these continuous data. If the value of the cross-correlation between the horizontal components of two different stations exceeds 0.6 for at least 10 pairs of station components in a given time window, we assume that an event signal is detected. The minimum and the maximum distances between two stations used for the cross-correlation are, respectively, set to $1 \mathrm{~km}$ and $100 \mathrm{~km}$. The source of these correlated signals is then located using a nonlinear least squares method that minimizes the error $e_{i j}$ between two stations: 


$$
e_{i j}=\Delta t_{i j}-\left(T\left(\mathbf{x}_{j}, \mathbf{x}_{0}\right)-T\left(\mathbf{x}_{i}, \mathbf{x}_{0}\right)\right),
$$

where $T\left(\mathbf{x}_{j}, \mathbf{x}_{0}\right)$ is the travel time between the station at $\mathbf{x}_{j}$ and the event at $\mathbf{x}_{0}$, and $\Delta t_{i j}$ is the measured travel time difference between two stations. The travel time is calculated using the New Zealand S-wave velocity model of Eberhart-Phillips et al. (2010) averaged over the regions of interest (see Additional file 1). Further details about the location procedure are provided in Ide (2012). A location uncertainty analysis was performed by comparing our locations of earthquakes with the location given by the GeoNet catalog (see Additional file 2: Figures S6, S7, S8 and S9). The results show that depth is not well constrained. Although the relative location may not be accurate, the ability of the method to distinguish different clusters seems well preserved.

\section{Removal of non-tremor events}

Although this methodology is successful in event detection, it does not distinguish between tremors, earthquakes, and other events, including misdetections. We therefore employ a scaling-law-based criterion that is a function of the seismic energy, seismic moment, and event duration. Ide et al. (2007) proposed that the seismic moment $M_{0}$ of slow earthquakes is proportional to the duration $T\left(M_{0} \propto T\right)$, whereas it is proportional to the cubed duration for fast earthquakes $\left(M_{0} \propto T^{3}\right)$. It is also known that the seismic energy $E_{\mathrm{S}}$ is proportional to the seismic moment $\left(E_{\mathrm{s}} \propto M_{0}\right)$ for a broad range of earthquakes (Ide and Beroza 2001), and also tectonic tremors (Ide et al. 2008). We can therefore employ different scaling relationships for earthquakes $\left(E_{\mathrm{s}} \propto T^{3}\right)$ and tremors $\left(E_{\mathrm{s}} \propto T\right)$. The scaled energy, which is the ratio between the seismic energy and seismic moment of an earthquake, has been proven to be different for tremors $\left(E_{\mathrm{s}} / M_{0} \sim 10^{-10}\right)$ and fast earthquakes $\left(E_{\mathrm{s}} / M_{0} \sim 10^{-5}\right)$, such that the coefficients of these two scaling laws are not equal (Ide et al. 2008). Since tremors are smaller energy events than fast earthquakes for a given event size, they must be separated from fast earthquakes using a criterion $C$ that is a function of $E_{\mathrm{s}}(\mathrm{J})$ and $T(\mathrm{~s})$ :

$$
\log \left(E_{\mathrm{s}}\right)-\log (T)<C \text {. }
$$

The quantity $\log \left(E_{\mathrm{S}}\right)-\log (T)$ is approximately constant for tremors since $E_{\mathrm{s}} \propto T$, but rapidly increases with duration for large earthquakes since $E_{\mathrm{S}} \propto T^{3}$. More details about the calculation of $E_{\mathrm{S}}$ and $T$ are given in Additional file 1 .

We compare $\log \left(E_{\mathrm{S}}\right)$ and $\log (T)$ for all the detected events in the Nankai region, Japan (Fig. 2a; Idehara et al. 2014), and the four study regions in New Zealand (Fig. 2b) using the cross-correlation method. The above criterion is efficient at separating tremors from earthquakes in the Nankai region due to a clear bimodal event distribution (Fig. 2a). However, this is not obvious for New Zealand (Fig. 2b), and it may explain why separating earthquakes and tremors is more difficult in New Zealand.

Here we choose $C=3.4$, which is adequate for tremors in the Nankai region (Fig. 2a). This criterion and the removal of any events with a duration of $<10 \mathrm{~s}$ allow us to reduce the number of possible tremors from 364,043 (after the cross-correlation) to 21,225.

Since our data still contain numerous earthquakes, with no clear separation, as shown in Fig. 2b, we also manually evaluate the likelihood of tremors via analysis
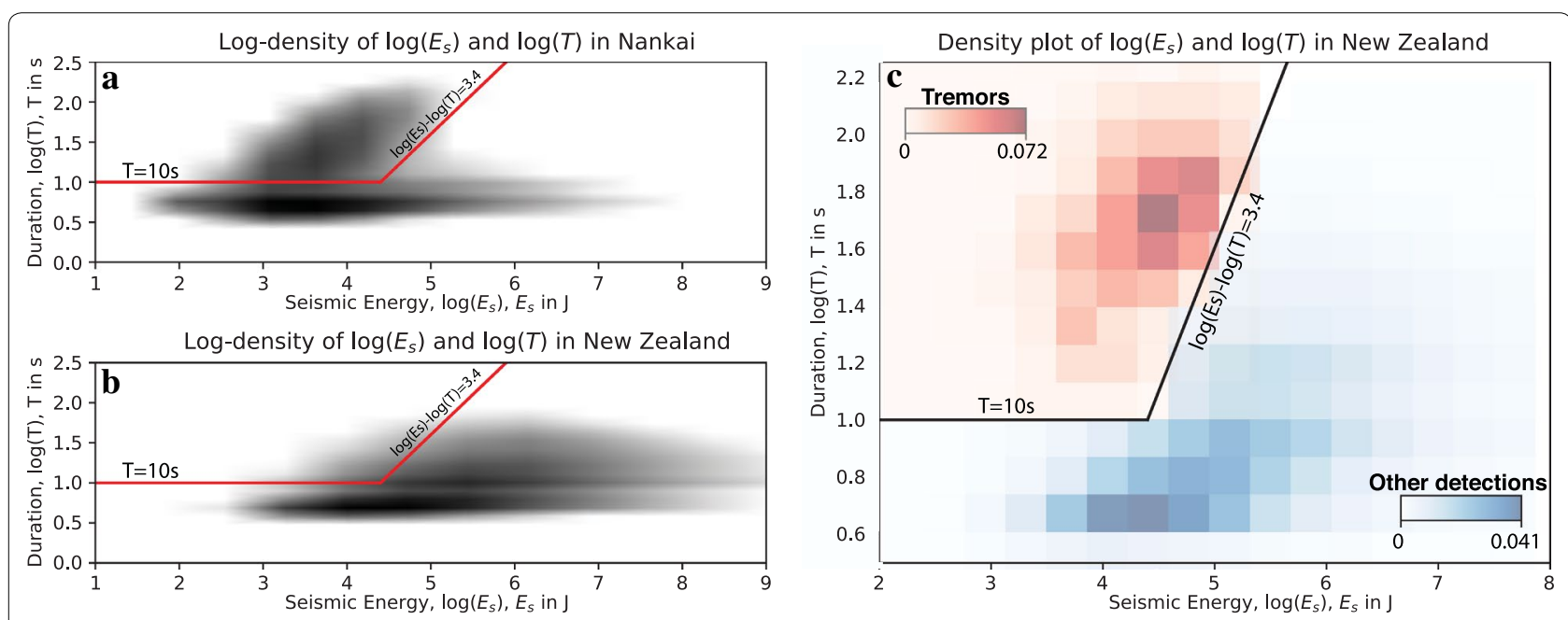

Fig. 2 a $\log \left(E_{s}\right)-\log (T)$ density plot for all the detected events in the Nankai Subduction Zone (Idehara et al. 2014). b Log $\left(E_{s}\right)-\log (T)$ density plot for all the detected events in New Zealand. $\mathbf{c} \log \left(E_{S}\right)-\log (T)$ density plot for the tremors and other detected events in New Zealand 
of the event location, waveform, and spectrogram. For the waveform, we applied a $2-8-\mathrm{Hz}$ band-pass filter to a 3000-s time window of seismic traces for the pair of stations where the thresholds are exceeded (Fig. 3). We confirm that the tremor duration is long ( $>30 \mathrm{~s}$ ), several bursts of the tremor sequence are visible ( $\geq 3$ times in the 3000-s window), and the signal is coherent among stations. On the spectrogram (see Additional file 2: Figure S1), we make sure that the detected event is not only composed of micro-seismicity, which is characterized by higher-frequency content than tremors (above $6 \mathrm{~Hz}$ ). If the event looks like a tremor, but the location is obviously out of the area of other detected tremors, the event was rejected. We identify 521 tremors across the four study regions. Due to the methodology (overlapping windows), some duplicates are present in the data. We chose to keep them both because they provide different information for location.

As a final check of the above criterion, Fig. 2c shows the density plot for the tremors and all other events detected in this study after handpicking. It appears that the value $C=3.4$ is a good compromise, as it appears to preserve the maximum number of tremors while rejecting the maximum number of other events, including misdetections. However, this verification can only be completed a posteriori. Even if the two distributions are not completely separated, which means that we are missing some tremors, this criterion allows us to discard a large number of earthquakes and handpick the tremor events.

\section{Results}

\section{Manawatu}

Manawatu is located in the central part of the North Island. Both triggered tremors (Fry et al. 2011) and ambient tremors (Ide 2012; Yabe et al. 2014) have already been discovered in this region. Here we extend the previous analysis of Ide (2012) to the 2005-2016 time period using a slightly different methodology. We detect 355 tremors that are concentrated along a southwest-northeast-oriented line (Fig. 4a), similar to the previous work of Yabe et al. (2014). These tremors appear to show a temporal recurrence pattern of $\sim 1$ year (Fig. $4 \mathrm{a}$ ).

Three deep SSEs occurred during our study period: 2004-2005 (Wallace and Beavan 2010), 2010-2011 (Wallace et al. 2012b; Bartlow et al. 2014), and 2014-2015 (Wallace et al. 2018), with each lasting for $\sim 1.5$ year. Two intermediate-depth SSEs were also reported, in 2006 and 2008 , with each lasting for $\sim 2-3$ months. Two of the maxima in tremor activity (Fig. 5a) correspond to known SSEs, the 2010-2011 and 2014-2015 SSEs.

Wallace et al. (2012b) and Bartlow et al. (2014) investigated the occurrence of the 2010-2011 SSE. They found that this SSE could be divided into three distinguishable phases during this restricted period: one lasting a week and starting at the end of May, another starting around the beginning of August and ending at the end of October, and the last starting at the beginning of December and ending at the beginning of March. They interpreted these SSE phases as multiple acceleration and deceleration phases. Similar SSE behavior has also been observed in Guerrero, Mexico (Frank et al. 2018). The corresponding tremor density in Fig. 5a shows a potential relationship between the picked tremor densities and acceleration/deceleration phases during this SSE. Although there is some temporal correspondence between the slow slip phases and tremor activity (Fig. 5a), we examine the potential spatial correspondence using the temporal slip inversion of Bartlow et al. (2014). The tremors are not located near the slow slip inversion results but rather $0.5^{\circ} \mathrm{N}$ of the slow slip inversion results (Additional file 2: Figure S2). It therefore appears difficult to spatially associate these tremors with only deep SSEs.

\section{Cape Turnagain}

Cape Turnagain is located in the southeastern part of the North Island. While no tremors have been reported in this region, five SSEs have been documented on the shallow $(<15 \mathrm{~km}$ depth) part of the subduction interface in the Hikurangi Subduction Zone since 2005. They started in June and August 2006 (Wallace and Beavan 2010), February 2008 (Wallace and Beavan 2010), the beginning of July 2011 (Wallace et al. 2012b; Bartlow et al. 2014), and midNovember 2016 (Wallace et al. 2017), respectively, with each SSE lasting 1-2 weeks. The mid-November SSE is thought to have been triggered by the Kaikoura Earthquake that occurred on November 13, 2016 (Wallace et al. 2017).

We detect 183 tremors that clearly occurred during three major episodes (Fig. 4b). The first tremor episode started on August 27, 2006, and ended on September 27, 2006, the second episode started on June 26, 2011, and ended on August 8, 2011, and the third episode started on November 20, 2016, and ended on December 10, 2011. These tremor episodes occurred during the same time periods as the SSEs inferred from geodetic data, highlighting a potential temporal relationship with regional SSEs. Although we do not detect tremors during the February 2008 SSE, we may have just missed these tremors due to an insufficient number of stations in operation during this time period.

Both onshore and offshore tremors are located in the region. They cover relatively wide areas, spanning more than $50 \mathrm{~km}$, with no distinguishable spatial clustering. We compare our tremor locations with the slip inversion of Bartlow et al. (2014) for the 2001 SSE (see Additional file 2: Figure S3) and observe that the tremors are located 

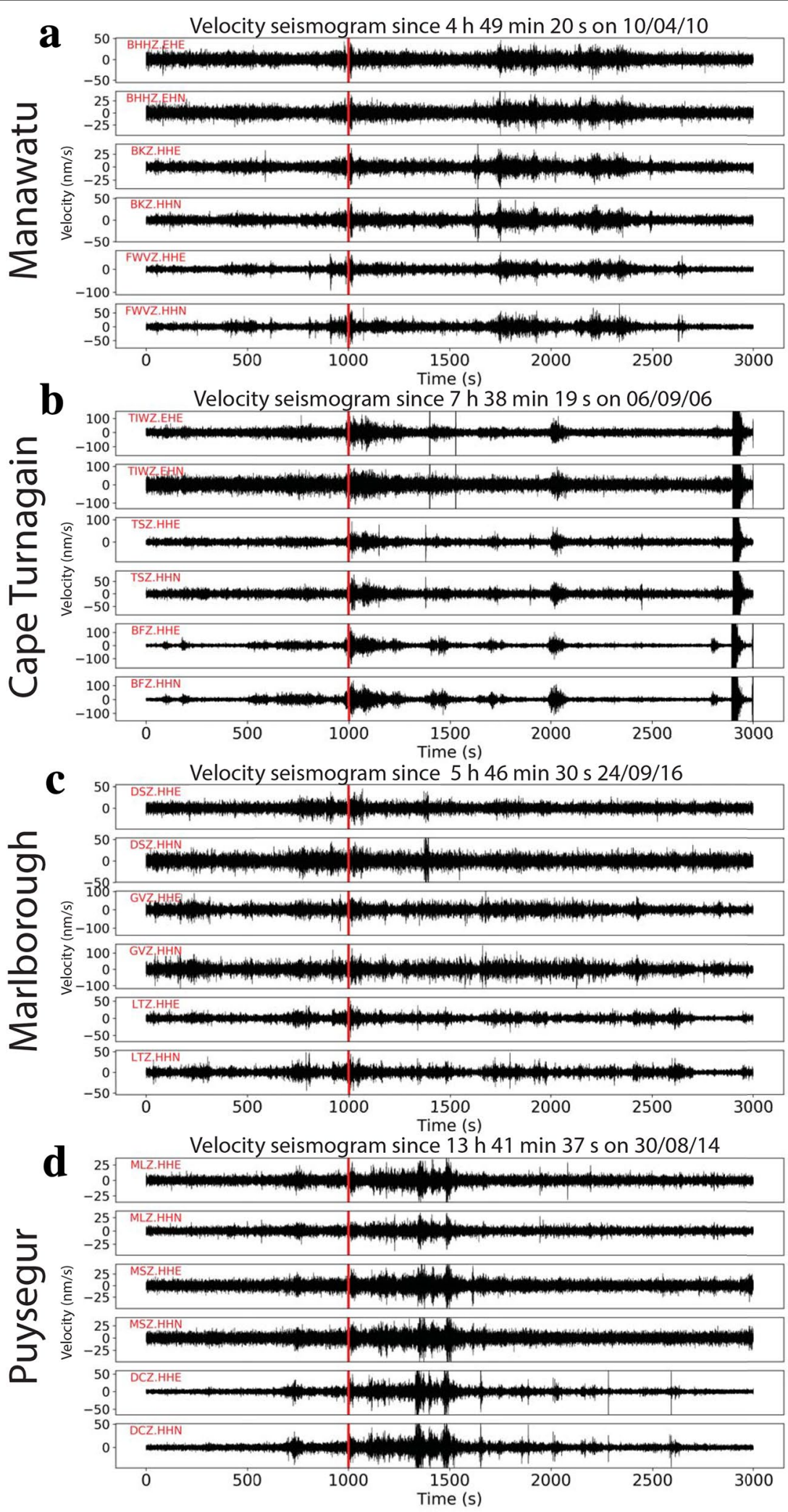

Fig. 3 Example of tremor velocity seismograms. Each seismogram is band-pass-filtered at 2-8 $\mathrm{Hz}$. The horizontal red line indicates the time the event was detected via the cross-correlation method 
$\mathbf{a}$
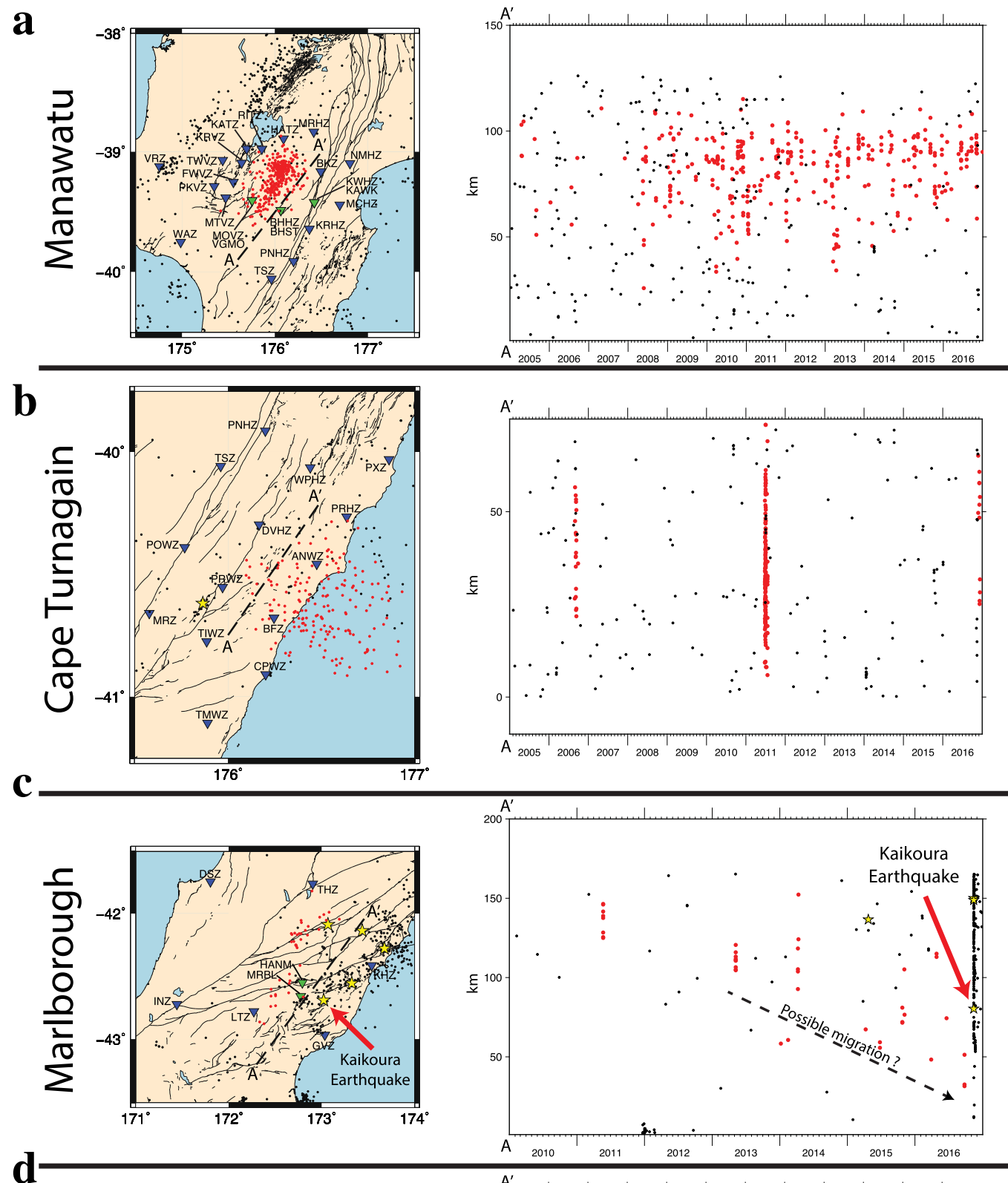

d
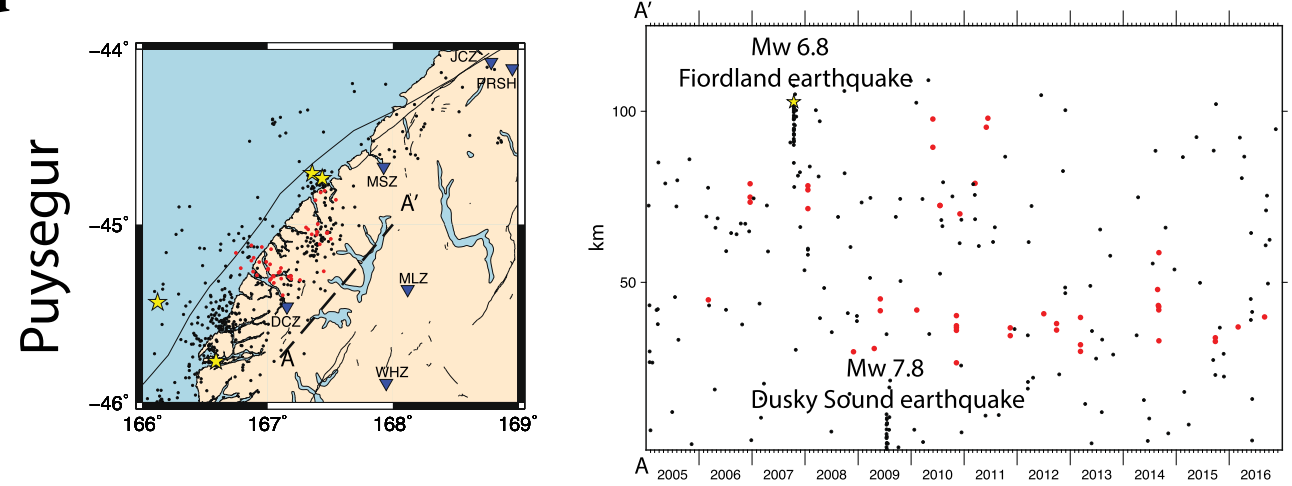


\section{(See figure on previous page.)}

Fig. 4 Location maps of the detected tremors (left) and their associated space-time projections in: a Manawatu; b Cape Turnagain; c Marlborough; and $\mathbf{d}$ Puysegur, New Zealand. Small black dots and yellow stars indicate $M w>4$ and $M w>6$ earthquakes, respectively. Inverted blue triangles indicate the seismic stations used in the tremor detection. Small red circles indicate the detected tremors. Reversed green triangles in $\mathbf{a}, \mathbf{c}$ indicate the GPS stations shown in Fig. 5. The A-A' profiles indicate the spatial coverage of the space-time projections

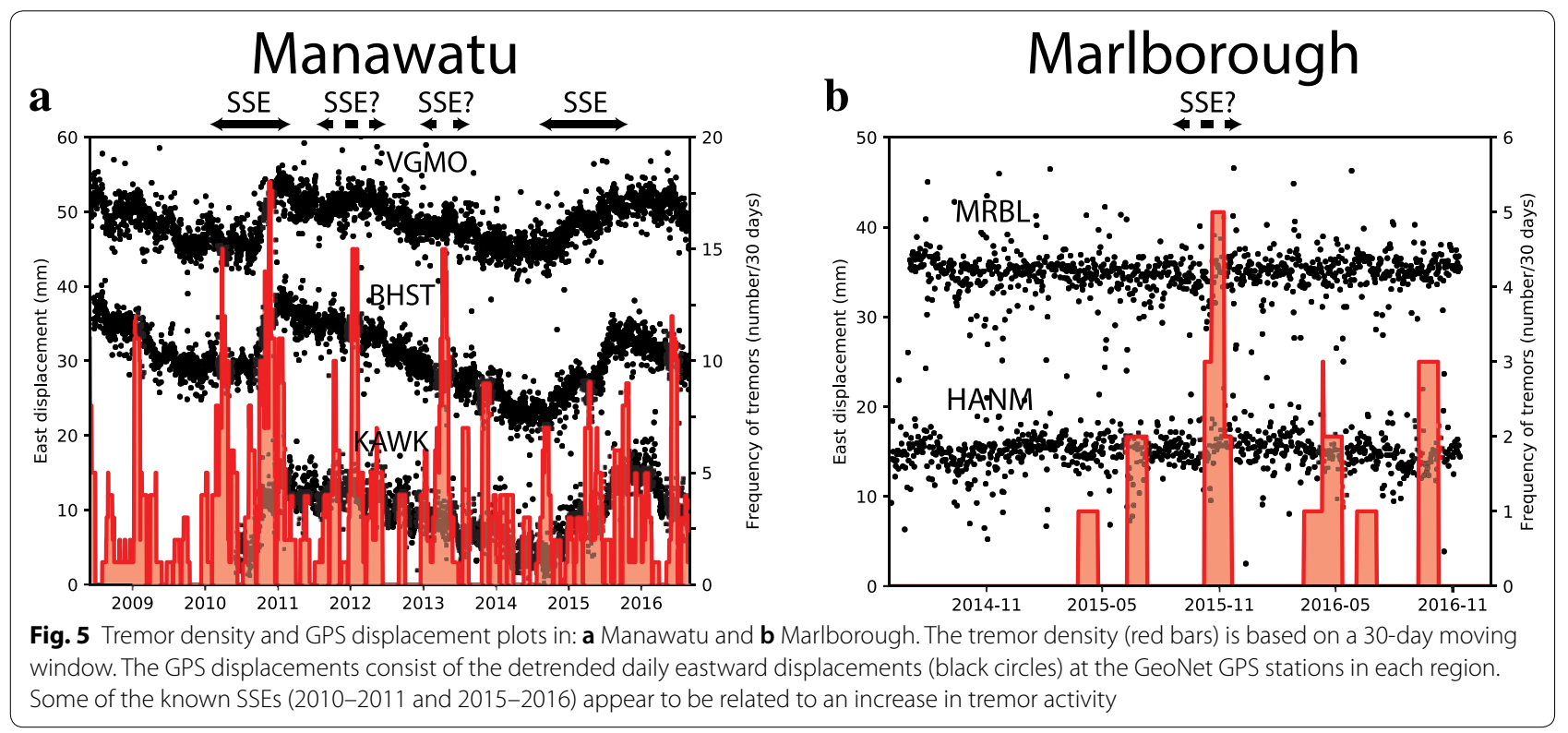

downdip of the SSE, which appears to be deeper than the swarm activity that also occurred during this time period.

\section{Marlborough}

This region undergoes a transition from Hikurangi subduction in the north to strike-slip motion on the on the Alpine Fault in the south through Marlborough Fault System. A recent study using the kinematic block model (Wallace et al. 2012a) advocates that this subduction has to accommodate some plate motion. Further supporting evidence comes from an analysis of afterslip following the Kaikoura Earthquake, with some of the slip occurring on the subduction interface (Wallace et al. 2018).

No tremors are detected in this region before 2010 . However, only six stations were used to detect the tremors, with this network only completed after the installation of station GFZ in February 2013. We detect 40 tremors to the northwest of the Kaikoura Earthquake epicenter (Fig. 4c). The fact that they are aligned with the Marlborough Fault System may be a hint that they are actually occurring on the Marlborough Fault System and not on the subduction interface. However, we were unable to firmly confirm this result mainly because of the small number of detected tremors.
We observe a southwestward migration of tremor activity since 2014, with the tremor locations approaching the Kaikoura Earthquake epicenter. We check this migration pattern by visual inspection of the eastward component of the velocity seismogram waveforms at stations THZ and LTZ (see Additional file 2: Figures S4 and S5). They exhibit a fairly periodic pattern, with tremor occurring every $\sim 6$ months.

\section{Puysegur}

Puysegur is located in the southwestern part of the South Island. The Alpine Fault, which accommodates the two reverse subduction motions of the North and South Islands, terminates to the north, and the Australian Plate starts to subduct beneath the Pacific Plate to the south. Three $\mathrm{Mw}>6.7$ earthquakes occurred during the 20032009 time period: the $2003 \mathrm{Mw} 7.2$ Fiordland, $2007 \mathrm{Mw}$ 6.7 Fiordland, and 2009 Mw 7.6 Dusky Sound Earthquakes (Fry et al. 2010). In 2009, small stress perturbation from the Dusky Sound Earthquake reactivated slip in the area of afterslip of the 2007 Fiordland Earthquake, suggesting that this region is prone to SSEs (Hamling and Hreinsdóttir 2016). Triggered tremors have also been detected in this region following the Kaikoura Earthquake (Peng et al. 2018). 
We detect 43 tremors in this region. This small number is probably due to the sparse network in this region. They clearly form two clusters that are located between the aftershock areas of the 2007 Fiordland and Dusky Sound Earthquakes (Fig. 4d), with a small gap of $\sim 20-25 \mathrm{~km}$ between the two clusters. They are also located downdip of the previous 2003 Fiordland Earthquake, assuming they are on the plate interface. It appears that the southern cluster has a recurrence pattern of $\sim 1$ year. The northern cluster does not possess any events that occurred after 2014.

\section{Discussion and Conclusions}

Here we report tremor detections in the Cape Turnagain, Marlborough, and Puysegur regions and also extend the analysis period of Ide (2012) in Manawatu. We use a cross-correlation method, followed by the implementation of a scaling-law-based criterion and handpicking, to construct our tremor catalog. This allows us to build a tremor catalog, focusing on four different regions, despite the active seismicity observed in New Zealand. The discovery of tremor in these regions suggests that tremor is actually a widespread phenomenon throughout New Zealand. Our catalog shows that the tremor bursts in Cape Turnagain temporally coincide with shallow SSEs. We also associate two tremor bursts in Manawatu with deep SSEs, but we note that not all tremor bursts can be related to known SSEs. We also discovered tremors near the Kaikoura and Dusky Sound Earthquake epicenters in Marlborough and Puysegur, respectively.

The interaction between ordinary and slow earthquakes has recently become an important research topic. Increasing evidence of earthquake triggering, with either slow slip triggering a fast earthquake (Ito et al. 2013; Ruiz et al. 2014) or an ordinary earthquake triggering an SSE (Itaba and Ando 2011; Zigone et al. 2012), supports the idea of a close interaction between slow and fast earthquakes (Obara and Kato 2016). Our study of New Zealand tremor provides further support for this idea. Although we detect only a small number of tremors in this region, we observe a distinct southwestward migration of tremors in the 3 years preceding the Kaikoura Earthquake. We note that poor seismic station coverage may have prohibited the detection of local tremors, with station GFZ only installed in early 2013 . While we cannot rule out the fact that we may have missed previous tremors in this region, the observed migration pattern seems to be reliable (see Additional file 2: Figures S4 and S5). Five tremors occurred from October 24, 2014, to November 5, 2015, time period. These tremors may be associated with the GPS signal at stations HANM and MRBL, whose eastward motion supports potential stress release (Fig. 5b). It is suggested that the subduction zone also accommodates some motion to the north of the South Island (Wallace et al. 2012a, 2018). While hypothetical, the Kaikoura Earthquake may be linked to slow processes that occurred prior to its nucleation. However, further investigation will be needed to confirm this hypothesis. The Puysegur Subduction Zone also shows spatially related tremors and large earthquakes, as well as some evidence supporting the presence of SSEs (Hamling and Hreinsdóttir 2016), making it a potentially interesting region for further investigations of the relationship between slow and fast tectonic processes.

\section{Additional files}

Additional file 1. Supplementary material.

Additional file 2. Supplementary figures.

Additional file 3. Tremor catalog (Manawatu).

Additional file 4. Tremor catalog (Marlborough),

Additional file 5. Tremor catalog (Puysegur).

Additional file 6. Tremor catalog (Turnagain).

\section{Acknowledgements}

Some figures of this manuscript were generated using the Generic Mapping Tools. P. R. greatly thanks Raymundo O. Plata-Martínez and Ta-Wei Chang for valuable discussions. P. R. is also grateful for interesting comments he received while he was visiting GNS science and Victoria University in New Zealand, particularly from Laura Wallace and Danielle Lindsay. P. R. and S. I. would like to thank the two anonymous reviewers as well as the editor David Shelly that helped a lot improving this manuscript.

\section{Authors' contributions}

PR wrote the manuscript and prepared the figures. SI provided the software used to detect and locate tremors. Both PR and SI contributed to the interpretation of data. Both authors modified and approved the final manuscript.

\section{Funding}

This project was supported by JSPS KAKENHI 16H02219 and MEXT KAKENHI $16 \mathrm{H} 06477$.

\section{Availability of data and materials}

The data used in this manuscript are from the GeoNet Network, publically available at https://www.geonet.org.nz/. The fault traces are available at https ://data.gns.cri.nz/af/. The tremor lists are available in Additional files 3, 4, 5, and 6.

\section{Competing interests}

The authors declare no competing financial interests.

Received: 24 January 2019 Accepted: 14 May 2019

Published online: 22 May 2019

\footnotetext{
References

Bartlow NM, Wallace LM, Beavan RJ, Bannister S, Segall P (2014) Time-dependent modeling of slow slip events and associated seismicity and tremor at the Hikurangi subduction zone, New Zealand. J Geophys Res 119(1):734753. https://doi.org/10.1002/2013JB010609

Beroza GC, Ide S (2011) Slow earthquakes and nonvolcanic tremor. Annu Rev Earth Planet Sci 39:271-296. https://doi.org/10.1146/annurev-earth -040809-152531
} 
Bird P (2003) An updated digital model of plate boundaries. Geochem Geophys Geosyst. https://doi.org/10.1029/2001GC000252

Delahaye E, Townend J, Reyners M, Rogers G (2009) Microseismicity but no tremor accompanying slow slip in the Hikurangi subduction zone, New Zealand. Earth Planet Sci Lett 277(1-2):21-28. https://doi.org/10.1016/j. epsl.2008.09.038

DeMets C, Gordon RG, Argus DF (2010) Geologically current plate motions. Geophys J Int 181(1):1-80. https://doi.org/10.1111/j.1365246X.2009.04491.X

Eberhart-Phillips D, Reyners M, Bannister S, Chadwick M, Ellis S (2010) Establishing a versatile $3-d$ seismic velocity model for New Zealand. Seismol Res Lett 81(6):992-1000

Frank WB, Rousset B, Lasserre C, Campillo M (2018) Revealing the cluster of slow transients behind a large slow slip event. Sci Adv 4(5):eaat0661. https://doi.org/10.1126/sciadv.aat0661

Fry B, Bannister S, Beavan J, Bland L, Bradley B, Cox S, Cousins J, Gale N, Hancox G, Holden C, Jongens R, Power W, Prasetya G, Reyners M, Ristau J, Robinson R, Samsonov S, Wilson K, the GeoNet team (2010) The Mw 7.6 dusky sound earthquake of 2009: preliminary report. Bull N Z Nat Soc Earthq Eng 43(1):24-40

Fry B, Chao K, Bannister S, Peng Z, Wallace L (2011) Deep tremor in New Zealand triggered by the $2010 \mathrm{Mw}$ 8. 8 Chile earthquake. Geophys Res Lett. https://doi.org/10.1029/2011GL048319

Hamling I, Hreinsdóttir S (2016) Reactivated afterslip induced by a large regional earth-quake, Fiordland, New Zealand. Geophys Res Lett 43(6):2526-2533. https://doi.org/10.1002/2016GL067866

Ide S (2010) Striations, duration, migration and tidal response in deep tremor. Nature 466(7304):356. https://doi.org/10.1038/nature09251

Ide S (2012) Variety and spatial heterogeneity of tectonic tremor worldwide. J Geophys Res. https://doi.org/10.1029/2011JB008840

Ide S, Beroza GC (2001) Does apparent stress vary with earthquake size? Geophys Res Lett 28(17):3349-3352

Ide S, Yabe S (2014) Universality of slow earthquakes in the very low frequency band. Geophys Res Lett 41(8):2786-2793. https://doi.org/10.1002/2014G L059712

Ide S, Beroza GC, Shelly DR, Uchide T (2007) A scaling law for slow earthquakes. Nature 447(7140):76-79. https://doi.org/10.1038/nature05780

Ide S, Imanishi K, Yoshida Y, Beroza GC, Shelly DR (2008) Bridging the gap between seismically and geodetically detected slow earthquakes. Geophys Res Lett 35(10):L10305. https://doi.org/10.1029/2008GL034014

Idehara K, Yabe S, Ide S (2014) Regional and global variations in the temporal clustering of tectonic tremor activity. Earth Planets Space 66(1):66. https ://doi.org/10.1186/1880-5981-66-66

Itaba S, Ando R (2011) A slow slip event triggered by teleseismic surface waves. Geophys Res Lett 38(21):L21306. https://doi.org/10.1029/2011GL049593

Ito Y, Obara K, Shiomi K, Sekine S, Hirose H (2007) Slow earthquakes coincident with episodic tremors and slow slip events. Science 315(5811):503-506. https://doi.org/10.1126/science.1134454

Ito Y, Hino R, Kido M, Fujimoto H, Osada Y, Inazu D, Ohta Y, linuma T, Ohzono M, Miura S, Mishina M, Suzuki K, Tsuji T, Ashi J (2013) Episodic slow slip events in the Japan subduction zone before the 2011 Tohoku-Oki earthquake. Tectonophysics 600:14-26. https://doi.org/10.1016/j.tecto .2012 .08 .022

Kaneko L, Ide S, Nakano M (2018) Slow earthquakes in the microseism frequency band $(0.1-1.0 \mathrm{~Hz})$ off Kii Peninsula, Japan. Geophys Res Lett 45(6):2618-2624. https://doi.org/10.1002/2017GL076773

Kim MJ, Schwartz SY, Bannister S (2011) Non-volcanic tremor associated with the March 2010 Gisborne slow slip event at the Hikurangi subduction margin, New Zealand. Geophys Res Lett. https://doi.org/10.1029/2011G L048400

Langridge R, Ries W, Litchfield N, Villamor P, Van Dissen R, Barrell D, Rattenbury M, Heron D, Haubrock S, Townsend D et al (2016) The New Zealand active faults database. N Z J Geol Geophys 59(1):86-96. https://doi. org/10.1080/00288306.2015.1112818

Nadeau RM, Dolenc D (2005) Nonvolcanic tremors deep beneath the San Andreas fault. Science 307(5708):389

Obara K (2002) Nonvolcanic deep tremor associated with subduction in southwest Japan. Science 296(5573):1679-1681
Obara K, Kato A (2016) Connecting slow earthquakes to huge earthquakes. Science 353(6296):253-257. https://doi.org/10.1126/science.aaf1512

Payero JS, Kostoglodov V, Shapiro N, Mikumo T, Iglesias A, Perez-Campos X, Clayton RW (2008) Nonvolcanic tremor observed in the Mexican subduction zone. Geophys Res Lett. https://doi.org/10.1029/2007GL032877

Peng Z, Chao K (2008) Non-volcanic tremor beneath the Central Range in Taiwan triggered by the $2001 \mathrm{Mw} 7.8$ Kunlun earthquake. Geophys J Int 175(2):825-829. https://doi.org/10.1111/j.1365-246X.2008.03886.x

Peng Z, Fry B, Chao K, Yao D, Meng X, Jolly A (2018) Remote triggering of microearthquakes and tremor in New Zealand following the $2016 \mathrm{Mw} 7.8$ Kaikoura earthquake. Bull Seismol Soc Am. https://doi.org/10.1785/01201 70327

Rogers G, Dragert H (2003) Episodic tremor and slip on the Cascadia subduction zone: the chatter of silent slip. Science 300(5627):1942-1943

Ruiz S, Metois M, Fuenzalida A, Ruiz J, Leyton F, Grandin R, Vigny C, Madariaga R, Campos J (2014) Intense foreshocks and a slow slip event preceded the 2014 lquique Mw 8.1 earthquake. Science 345(6201):1 165-1169. https:// doi.org/10.1126/science.1256074

Shelly DR, Beroza GC, Ide S (2007) Non-volcanic tremor and low-frequency earthquake swarms. Nature 446(7133):305-307. https://doi.org/10.1038/ nature05666

Todd EK, Schwartz SY (2016) Tectonic tremor along the northern Hikurangi margin, New Zealand, between 2010 and 2015. J Geophys Res 121(12):8706-8719. https://doi.org/10.1002/2016JB013480

Todd EK, Schwartz SY, Mochizuki K, Wallace LM, Sheehan AF, Webb SC, Williams CA, Nakai J, Yarce J, Fry B et al (2018) Earthquakes and tremor linked to seamount subduction during shallow slow slip at the Hikurangi margin, New Zealand. J Geophys Res. https://doi.org/10.1029/2018JB016136

Wallace LM, Beavan J (2010) Diverse slow slip behavior at the Hikurangi subduction margin, New Zealand. J Geophys Res. https://doi. org/10.1029/2010JB007717

Wallace LM, Beavan J, McCaffrey R, Darby D (2004) Subduction zone coupling and tectonic block rotations in the North Island, New Zealand. J Geophys Res. https://doi.org/10.1029/2004JB003241

Wallace L, Barnes P, Beavan J, Van Dissen R, Litchfield N, Mountjoy J, Langridge R, Lamarche G, Pondard N (2012a) The kinematics of a transition from subduction to strike-slip: an example from the central New Zealand plate boundary. J Geophys Res. https://doi.org/10.1029/2011JB008640

Wallace LM, Beavan J, Bannister S, Williams C (2012b) Simultaneous longterm and short-term slow slip events at the Hikurangi subduction margin, New Zealand: implications for processes that control slow slip event occurrence, duration, and migration. J Geophys Res. https://doi. org/10.1029/2012JB009489

Wallace LM, Kaneko Y, Hreinsdóttir S, Hamling I, Peng Z, Bartlow N, D'Anastasio E, Fry B (2017) Large-scale dynamic triggering of shallow slow slip enhanced by overlying sedimentary wedge. Nat Geosci. https://doi. org/10.1038/NGEO3021

Wallace LM, Hreinsdottir S, Ellis S, Hamling I, D'Anastasio E, Denys P (2018) Triggered slow slip and afterslip on the southern Hikurangi subduction zone following the Kaikoura earthquake. Geophys Res Lett. https://doi. org/10.1002/2018GL077385

Wech A, Boese C, Stern T, Townend J (2012) Tectonic tremor and deep slow slip on the alpine fault. Geophys Res Lett. https://doi.org/10.1029/2012GL051751

Yabe S, Ide S, Yoshioka S (2014) Along-strike variations in temperature and tectonic tremor activity along the Hikurangi subduction zone, New Zealand. Earth Planets Space 66(1):142. https://doi.org/10.1186/s4062 3-014-0142-6

Zigone D, Rivet D, Radiguet M, Campillo M, Voisin C, Cotte N, Walpersdorf A, Shapiro NM, Cougoulat G, Roux P et al (2012) Triggering of tremors and slow slip event in Guerrero, Mexico, by the 2010 Mw 8.8 Maule, Chile, earthquake. J Geophys Res 117:B09304. https://doi.org/10.1029/2012J B009160

\section{Publisher's Note}

Springer Nature remains neutral with regard to jurisdictional claims in published maps and institutional affiliations. 